\title{
Experiential Learning in the Energy Based Classroom
}

\author{
https://doi.org/10.3991/ijep.v11i6.16539
}

Cole Maynard, Jose Garcia, Anne Lucietto, William Hutzel, Brittany Newell ${ }^{(凹)}$

Purdue University, West Lafayette, United States

bnewell1@purdue.edu

\begin{abstract}
Engineering technology students revel in enhanced learning experiences that include the use of hands-on methods to teach the real-world usage of technical material. These learning experiences increase applied knowledge and retention in students and others in related STEM fields. Using research-based learning theory in a project-based and team-based learning environment, the course developers transformed the learning experience from sterile lecture type courses to interactive experiences that enhance and build on the course concepts. Course surveys were used to collect information from students to further understand how changes to the course delivery impacted them and affected the learning environment. The goal of this research is to further delve into the use of personalized learning to engage and encourage student growth. Initial results suggest improved student engagement, and engagement with course materials as a result of the transformation of class delivery. Evidence shows that the classroom experience is enhanced by this type of activity. Supporting findings by researchers in other areas show that experiential or active learning improves students' understanding and engagement with concepts taught through project-based learning methods.
\end{abstract}

Keywords-Active learning, student engagement, engineering technology, research-based learning theory

\section{Introduction}

Energy is the fundamental concept that links multiple topics within technical fields including materials processing, electricity, mechanics, fluids, and thermodynamics. This research looks specifically at two sequential thermodynamics courses in an engineering technology program and how the implementation of an applied learning approach impacts the student's perception and engagement of the course materials. This article is intended to demonstrate that the synergy between these two energy-based courses with embedded projects and changes to course design is an effective means to engage and encourage learning. To achieve these objectives, major course changes were needed. Additionally, it was deemed necessary to provide a theme of renewable energy throughout the two courses, a team-based applied learning approach, and the addition of technical projects. 
To delve into this work, it was important to understand how students perceived the technical projects, and how their learning environment was impacted. Students provided feedback about course changes through a survey administered through a computer-based surveying tool. Prior research on engineering technology students showed that students excel within experiential learning environments [1]. Therefore, the development of the technical projects was especially critical to not only engage students, but to begin building an environment that is supportive of the way they learn, rather than simply placing these students in a traditional classroom environment [2].

The two Mechanical Engineering Technology (MET) courses have a focus on thermodynamics. Thermodynamics is a physical science which focuses on heat and its relations to other forms of energy [3]. Each of these courses take place during the spring and fall semesters, and regularly have an enrolment between 70 and 100 students. The first of the two courses focus on the concepts surrounding heat transfer and introduces students to phase diagrams. The second thermodynamics course expands upon the concepts introduced in the first course and teaches the students how to apply such concepts in real-world applications. The second course was previously focused heavily on theory and incorporated no laboratory type projects to further expose students to the concepts being taught, unlike the first of the two courses which has a weekly lab experience. As the second of the two courses takes a deeper dive into concepts taught within the first course, this study is focused on measuring only the student responses within the second of the two thermodynamics courses, and how the inclusion of technical projects impacted how students perceived and understood the concepts being taught.

The remainder of this article is organized in the following manner. First, a literature review as well as a descriptive overview of the technical projects is presented within section two. Following this, the research questions used throughout this effort are illustrated within section three. Next, the methods section describes the development of the student surveys as well as the specific methods used to compare the collected data. Section five contains the results gathered as a result of implementing the two technical projects in addition to student perceptions of the two thermodynamics courses. Lastly, the results are discussed, conclusions are drawn, and the future work surrounding this research effort is indicated within section six.

\section{Literature review}

Energy concepts within thermodynamics, are commonly viewed to be amongst the most difficult subjects to study and conceptually understand [4]. Many times, students get stuck in the early stages of complex problem solving within thermodynamic concepts as they do not fully understand the material or have misinterpreted it [5]. The ability to effectively convey course concepts is dependent on the ability to motivate students [6]. Team-based interactive learning activities have been found to motivate students and more effectively convey course concepts [7] [8]. The concept of students collectively working on a team to solve technical problems is often referred to as teaming. Teaming has been proven to lead to higher student achievement [9] as well as in- 
creased levels of understanding [10]. Measuring how students feel about team interactions is crucial for maintaining a productive teaming environment [11]. Surveys were chosen as the appropriate means to evaluate how working in teams impacted the student's perception of projects. As a means to improve this team-based learning approach, instructors pursued the implementation of scaffolded learning throughout the two courses [12] [13]. The use of a scaffolded learning pedagogical approach allows for students working within teams to understand and learn concepts better than if working alone [14]. Furthermore, the positions filled by technical graduates of the program rely upon peer collaboration and cross-disciplinary research for development of new products, ideas, and projects [15]. Incorporation of team activities into formal learning environments provides experiences that build teamwork skills and leadership qualities that employers desire [16] [17] [18].

A challenge encountered by the instructors is the presence of a lab for the first course, but not for the second. Team-based projects are now included in the second course to compensate for the lack of interactive time. However, the projects do not include less in class time, which is needed to increase learning of the team and develop projectbased skill sets [19] [20]. The addition of relevant, hands-on projects further fulfills the programmatic goals of incorporating active learning in every classroom. The changes made within the two courses were fully incorporated so that all future sections of these courses will contain the modifications made.

The use of competency-based learning (CBL) is an additional method for motivating students. CBL provides students with the opportunity to demonstrate their understanding of concepts within a specific area of study [21]. One methodology to encourage student progression through the stages of learning a concept is the assembly of course information together in a creative way [22], often using experiential projects. Utilizing a project-based, experiential learning environment often encourages the development of greater problem-solving skills [23]. Additionally, student's attention and motivation surrounding various concepts can be improved through hands-on pedagogical approaches [16].

\subsection{Project design}

This research modifies two required mechanical engineering technology courses, MET 22000 Heat Power and MET 32000 Applied Thermodynamics. The intent of the course instructors was to build continuity between the two courses, with the first introducing the requisite topics and the second providing a deeper study of thermodynamics. Bloom's Taxonomy [22] [24] was used throughout the transformation of the two courses by following a set of six skills which organize educational objectives and promote higher level thinking known as the cognitive process dimension. The use of such educational objectives prompts the assessment of concepts which are to be clearly learned by the students [25]. This was done by incorporating common learning objectives between the two courses and adding a renewable energy section to each course. The first course now includes a tour of the photovoltaic solar panels and polyethylene glycol solar heating panels installed on the roof of the technology building. This tour is 
intended to increase student knowledge by providing the opportunity to learn the functionality of the system. Students in the first course construct a piping diagram of the components used in the solar heating system. The second course builds on the tour experience by conducting an analysis of the photovoltaic (PV) array of the actual solar system using instructor-designed modules. Analysis of this infrastructure provides students with a well-founded understanding of a real-world renewable energy application. Thus, providing student learning enhancement through experiential learning activities and tasks that utilize the knowledge gained through the activities presented in both courses.

As a means of improving the performance of students within the classroom, a handson active learning environment is pursued using technical projects [26]. Technical projects are proven to be a successful technique for creating active learning environments [13]. These projects must follow the progression of complexity and specificity highlighted within the guidelines of Bloom's Taxonomy to ensure the activities follow the cognitive process dimension [22] [24].

Of the two courses discussed in this paper, the first course was designed to include technical projects in the laboratory. The second course, as a lecture course, did not have an accommodation for the hands-on activities. The lack of hands on activities within the second of the two courses, allows researchers to measure the impact of technical projects and how their inclusion impacts student's learning. The instructor then pursued adding two technical projects for inclusion in the second course with the intent of enhancing the student's learning experience.

The first technical project was designed to have a centralized focus on solar energy to align with the materials presented in both courses. The second technical project investigates power cycles and Stirling engines. The breakdown of the two projects, is described by Maynard et al., [27] as:

- Technical Project 1 Focus: Solar Energy [28]

- Primary Task:

Measure Current, Voltage, Power Output on small solar panels

- Secondary Task: Charge Cell Phone using provided small solar panels and Analyze data a from real-world system implemented on campus

- Student Learning Takeaways:

Improved Team Communication/Interaction, Electrical Circuit Design, PV Array Functionality, Utility of Solar Energy, Understanding of Energy Transfer, Increased Problem-Solving Skills, Power Losses, and Characteristics of LightBased Energy.

- Technical Project 2 Focuses: Power Cycles \& Stirling Engines

- Primary Task:

Design a System to Raise Material of Known Weight (quarter or dime) Using Tea Light Candle as Energy Source

- Secondary Task:

Written Technical Bulletin, Verbal Explanation of Process and Measurements, Demonstration of Energy Conversion 
- Student Learning Takeaways: Improved Team Communication/Interaction, In-Depth Look at Energy Sources and their Qualities, Energy Conversion Processes, Losses within Energy Conversion, and System Efficiencies.

The pedagogy utilized throughout the courses followed Bloom's Taxonomy [22] [24] as a guide. Within MET 32000, the second of the two courses in applied thermodynamics, students learn about alternative forms of renewable energy including solar, hydroelectric, biomass, and wind within a lecture and through the completion of an Introduction to Renewable Energy Certificate from Solar Energy International. The certification short course enhanced their learning and understanding of the concepts [29]. Students were then provided the opportunity to apply, analyze, evaluate, and create a solar energy system using data from the system shown in Figure 1. They were given two to three weeks to complete each technical project while working in teams of three to four students. Team members were selected by the instructor for each project. Teams were tasked with measuring current, voltage, and power for a set of small solar panels in series and parallel and at various angles and lighting environments (indoor fluorescent lights versus outdoor sunlight). Additionally, they also used solar panels to charge their cell phones as a demonstration of the utility of solar energy and to provide an understanding of power transfer requirements. After the physical demonstration, teams were asked to determine how solar panels work and the critical design criteria that must be considered when designing photovoltaic arrays. They utilized this knowledge and the knowledge gathered from solar cell circuit creation to analyze online data from the photovoltaic array designed and maintained by Purdue's Applied Energy lab. This is an array of solar panels physically located on the top of the technology building as seen within Figure 1. Students toured the photovoltaic array in the first thermodynamics course and then analyzed the system's output within the second course providing continuity between the two courses.

The pedagogy of the second project was focused on construction of energy conversion devices and followed the cognitive process dimension of Bloom's Taxonomy. The topics are introduced through course reading assignments on power cycles and Stirling engines in addition to lecture material, here students are asked to remember and understand these concepts. Students apply this knowledge to cycle problems which asked them to analyze and evaluate systems. Two Stirling engines were brought to class as demonstrations and the class discussed how each process worked enhancing their understanding of the material. Teams were then asked to create a system to raise a material of known weight (a quarter or dime) using only the energy from a tea light candle as depicted in Figure 2. Figure 2 shows various solutions from students including pressure-based designs, cantilever systems, and pop-pop steamboats. Team deliverables for this work were a written technical bulletin explaining the process and measurements taken to measure energy conversion along with an in-class demonstration and explanation of the conversion mechanism. 
Paper-Experiential Learning in the Energy based Classroom

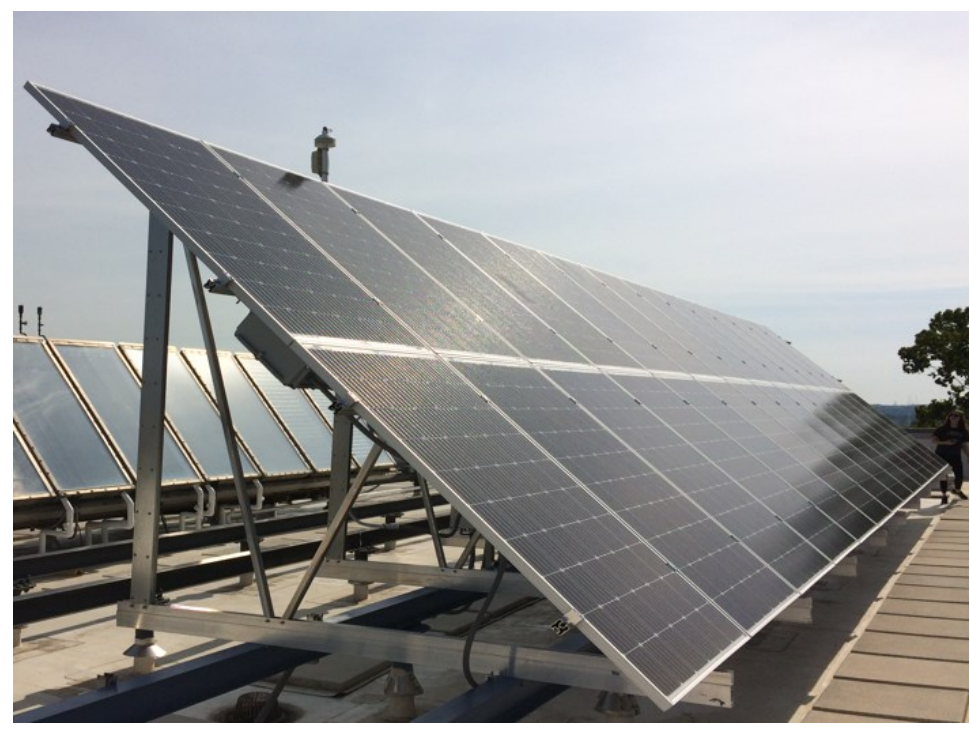

Fig. 1. Purdue Applied Energy Lab Photovoltaic Array
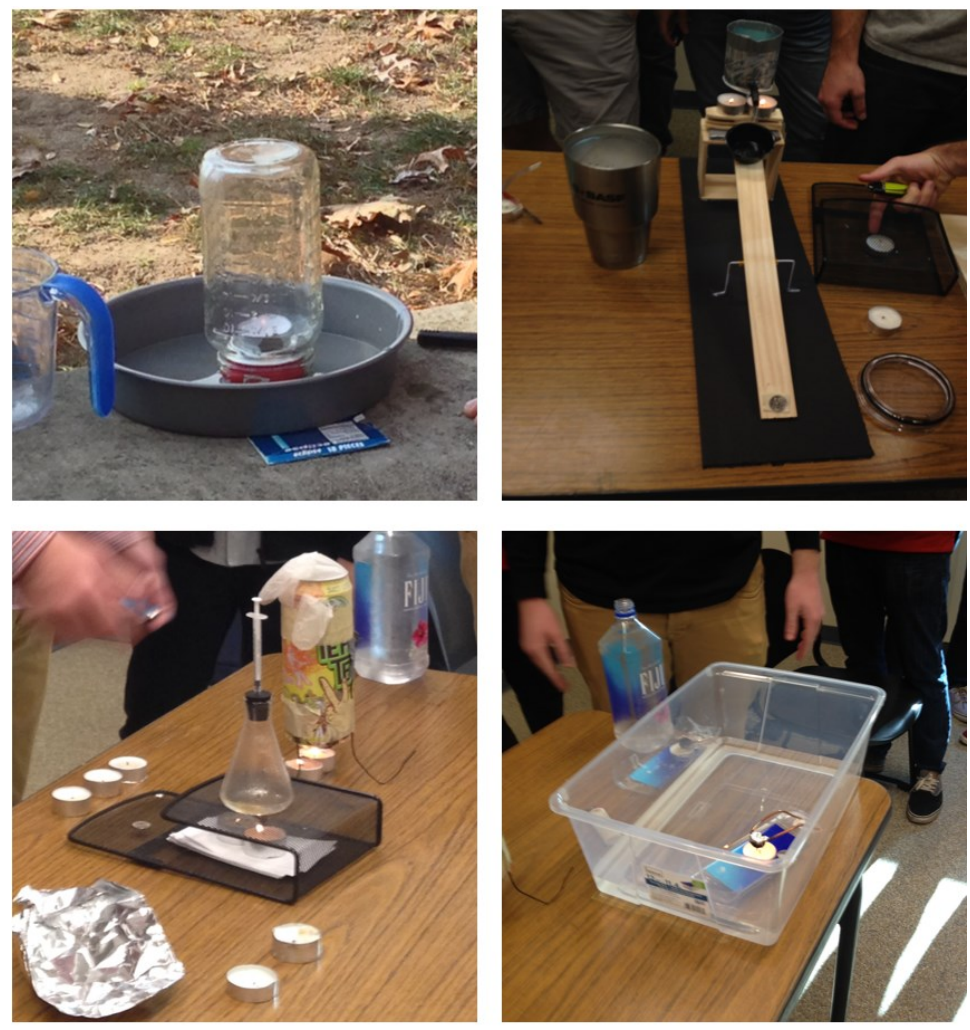

Fig. 2. Technical Project 2: Student Built Heat Engines 


\section{Research questions}

There are two research questions used to evaluate the creation and implementation of the projects and surveys. The two questions will direct the research to pursue the best methods to create these classroom projects and allow the researcher team to quantify the student's perception.

- Do project-based experiences influence the learning of engineering technology students in thermodynamics?

- Do real-world, experiential projects improve engineering technology students' understanding of thermodynamic concepts?

The answers to these questions will be determined using an analysis of student responses to the surveys. This analysis will also provide input into adjustments to the courses that will benefit the students.

\section{$4 \quad$ Methods}

Surveys incorporating Likert-type scales were developed to identify the student reaction to the course and the projects added [30]. Questions within the survey focused on three areas, the solar energy project, the energy conversion project, and the course overall. As the implementation of the course project took place in the second, more advanced course, only the students within this class were administered the project surveys. The results from these project focused surveys are the results reviewed in this work. The anonymous survey data was collected through Qualtrics.

\subsection{Student surveys}

The survey questions address student interest in topics and their self-evaluated level of knowledge of technical project topics and teamwork. Assessing student interest here is especially important as their attitude in approaching technical problems greatly impacts the way in which they grasp theoretical concepts such as those within thermodynamics [31]. Students were assessed on the same metrics pre and post intervention. The self-reported information collected from the students contains both quantitative and qualitative data. The results of this transformation focus primarily on the quantitative data which is used to draw statistical conclusions. The qualitative data gathered is a result of the short answer responses the students provide about the project and the course overall. Data was taken within the second thermodynamics course, MET 32000 where the technical projects were executed. This course had one lecture section per semester. The course was studied across two consecutive semesters with the same instructor. In the first semester, there were 96 students in the course and in the second, there were 94 students in the course. All students were asked to complete the surveys and the two groups were merged for the analysis. 


\subsection{Data comparison}

To define the student population, descriptive statistics were used when analyzing each quantitative survey question. The content analysis method was used for assessing the qualitative data from the student survey results [32] [33]. The descriptive statistics reveals information such as how the student population viewed the energy project, and how it impacts their perceived knowledge surrounding topics of thermodynamics. Content analysis provides valid inferences from the student responses if the responses are properly coded, the data comparison will reveal critical information to the instructors about the design and implementation of the technical projects within their course. Results from the analysis indicate the way in which the projects are impacting the students, what are the key takeaways the students have upon the completion of the projects, in addition to changes or improvements that could be made.

\section{$5 \quad$ Results}

The general course assessments were made at the beginning and end of the second thermodynamics course and asked for student opinions on the course delivery. Technical project assessments based on the topics of renewable energy and heat and work conversion were made pre and post technical projects 1 and 2. These surveys asked students about their interest in the topics and opinion on their gain in level of knowledge. All assessments were made using Qualtrics and were distributed electronically to the students as a whole to facilitate the collection of anonymous responses. Students expressed satisfaction with course materials and example problems in MET 32000. Students shared that they were impressed with the level of hands on activities in the course that was previously noted as lecture only. Upon comparing pre and post survey data, students indicated that their motivation towards learning thermodynamic concepts increased as a direct result of the technical projects. Further information about the findings from each project and the course overall is described in the next section.

\subsection{Technical project 1 - Solar energy}

The first technical project was included with the intent of increasing the students' understanding of concepts surrounding renewable energy. The first task of the technical project is for students in class to execute a hands-on activity with small $5 \mathrm{~V}$ panels. Students wire the panels in series and parallel and measure the current, voltage, and power outputs. They compare measurements taken with the panels in the classroom under fluorescent lighting to the outdoor environment. They also tilt the panels using a stand to 3 different angles and compare the panel output. After, experimentation they use solar panels to execute a real-world application, charging their cell phones. They in turn use this knowledge when analyzing the larger scale system on the roof of the technology building to determine the efficiencies of active photovoltaic systems for electricity generation. In this analysis, students first focused on system losses. Significant features that influence efficiency, as well as ways to further increase efficiencies were included in the discussion and technical write-up. The second project component 
is furthering student understanding of how photovoltaic solar panels work. Further consideration and discussion focused on the implementation of solar power, and the potential cost savings associated with this means of generating power. Groups generated a technical report based upon the work. It was prepared to highlight how these panels work, produce sample calculations, sketches/diagrams, and efficiencies.

Survey questions focused on technical project 1 asked students to evaluate their perceived level of knowledge of renewable energy before and after technical project 1 . The responses were made on a five-point Likert scale where a (4) represented expert level knowledge, and a (0) being beginner level knowledge. Students primarily indicated a mid-level of knowledge for perceived level of knowledge of renewable energy with $58.08 \%$ rating themselves as a (2) pre-technical project 1 . Upon the completion of technical project 1 , students expressed a more in-depth level of knowledge with $65.89 \%$ rating themselves as a (3) and $8.53 \%$ deeming themselves proficient with a (4). The shift in student responses pre and post project can be seen in Figure 3.
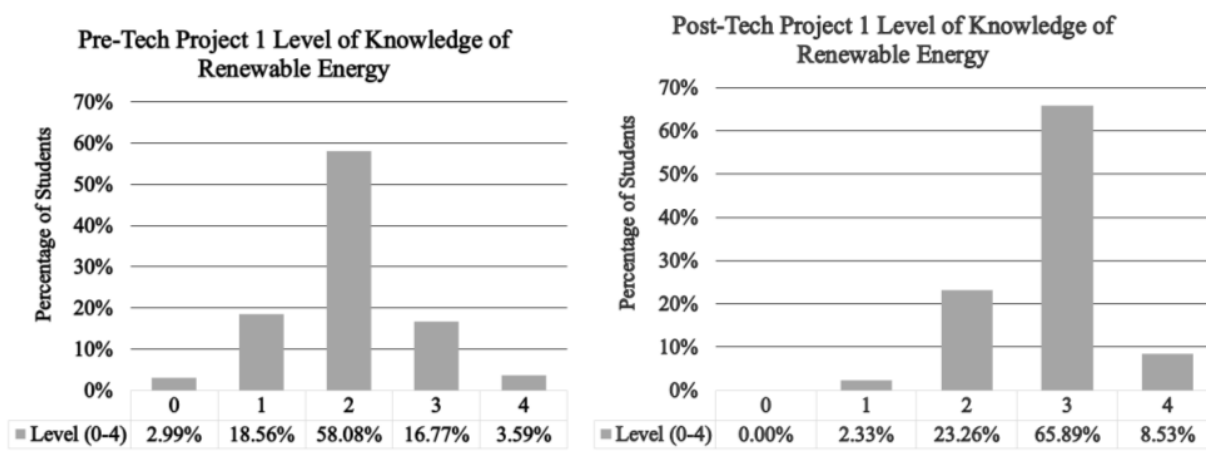

Fig. 3. Student Responses to Knowledge of Renewable Energy

Figure 4 shows students perceived understanding of solar energy. Students specified their understanding level on a 10-point Likert scale, where the highest score represents expert level and the lowest represents beginner. The histograms show a shift in responses towards a greater level of perceived understanding. The most frequent student response before the project was a (5), representing a fair level of understanding on the scale. Upon completion of the project, students felt they had an understanding level of (7) or a good understanding. The two-point shift in response supports an assertion that technical project 1 increased the students perceived understanding using the hands-on active learning environment fashioned through the solar energy project. 

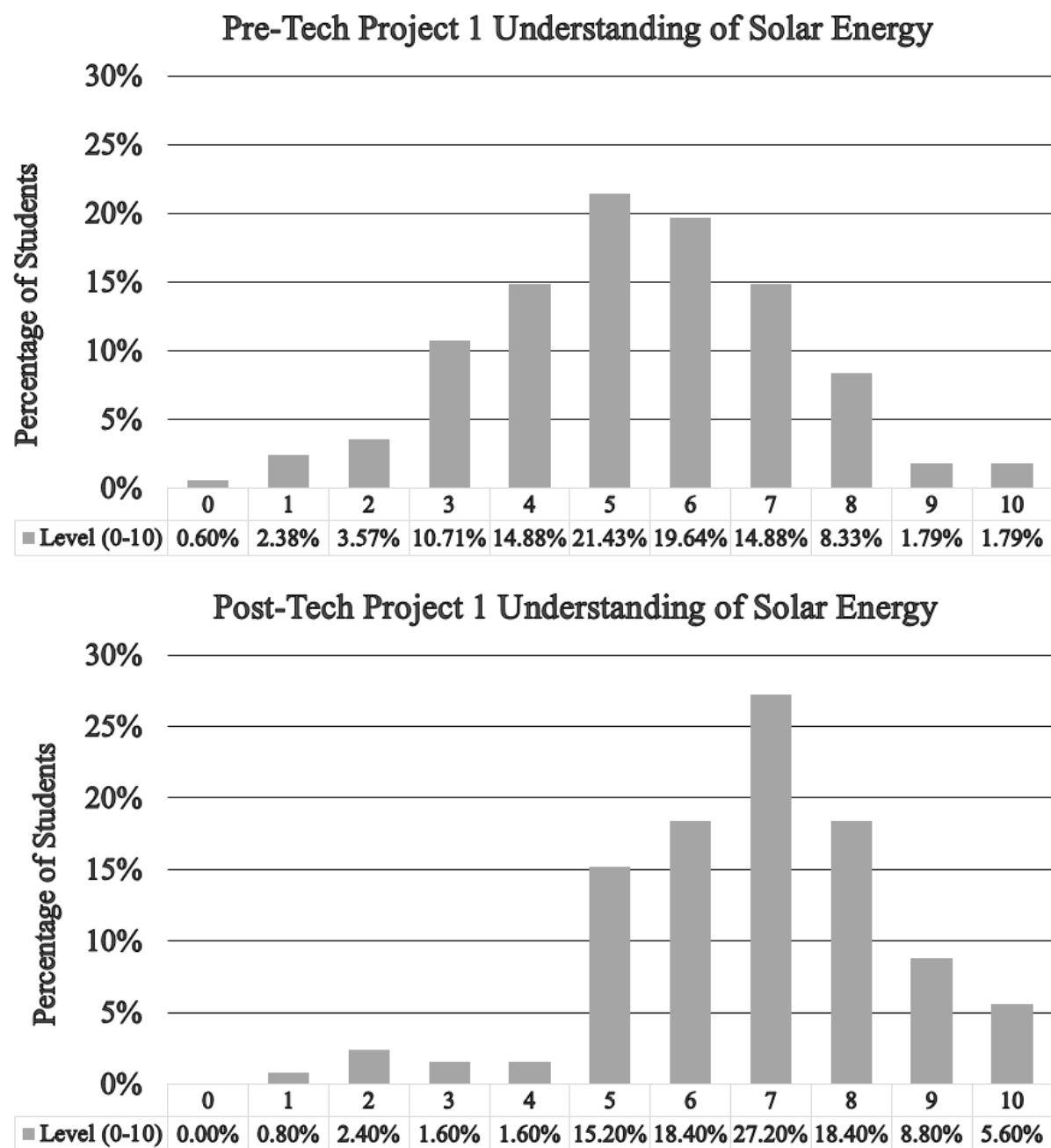

Fig. 4. Student Responses to Understanding of Solar Energy

Pre and post data comparisons from the first technical project show that students initially were interested in a broad range of energies including wind, nuclear, and petroleum-based sources. However, post project surveys found a focused interest in solar energy in addition to an increase in its importance as a renewable energy source. There was a greater than $20 \%$ increase in student recognized importance of solar energy. Many students expressed their interest in solar energy increased as a result of the energy project amid short answer responses. One student described the project as being “...interesting because we focus on the environmental benefits and how we can effectively capture sunlight to produce energy..." 
Figure 5 evaluates the students' view on their potential of working with renewable energies in a future job. Upon familiarization with solar energy, how it impacts everyday life and its importance, students felt they were more likely to work with renewable energy concepts in their future. Nearly $18 \%$ of the students do not believe they will use renewable energy concepts within their careers, this notion remained relatively constant even at the completion of the project. However, when viewing the "maybe" category for this question both before and after the first technical project, the number of students who believed they would use renewables in their careers decreased by nearly $5 \%$ with their responses shifting from "yes" to the "maybe" category. These results could be attributed to the students gained knowledge of renewables and its associations with job markets which they associated themselves with. Students overall found the project to be "...very interesting and applicable to my future...", while others indicated its potential impact on their future career stating that the project provoked "...a strong interest in renewable energy".
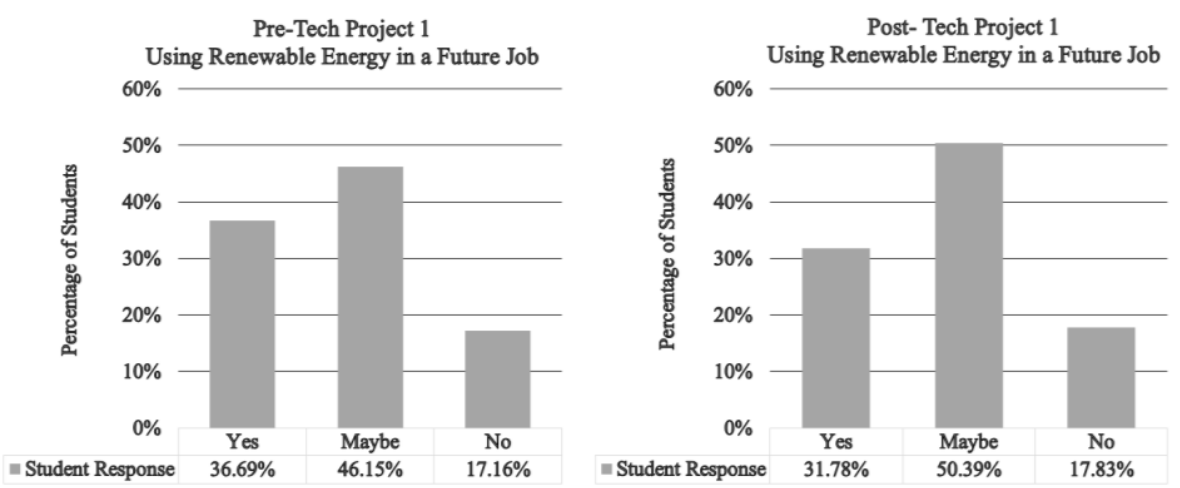

Fig. 5. Student Responses to Future Use of Renewable Energy

The final question from the solar project evaluated how the students felt about teaming as a result of the project. Here students were asked how important they believe teamwork will be in their future career. This was a categorical based response that was asked before and after the project. The response options were built into a five-point scale and ranged from students believing that teamwork is not at all important in their future career to teamwork being extremely important in their future career. The obtained responses can be seen below in Figure 6. As this data was qualitative, content analysis was needed to transform the responses in order to generate descriptive statistics about the student responses. This was done by assigning a number value from four to zero to each of the categorical response option. Four represents the response of extremely important and zero represents not important. The quantified student responses show a mean pre-assessment response of 3.38. A value which represents responses between extremely (4) and very (3) important. Upon the completion of the project a mean score of 3.63 was recorded. Showing that students placed an improved emphasis on the importance of teamwork in the students' future careers. 


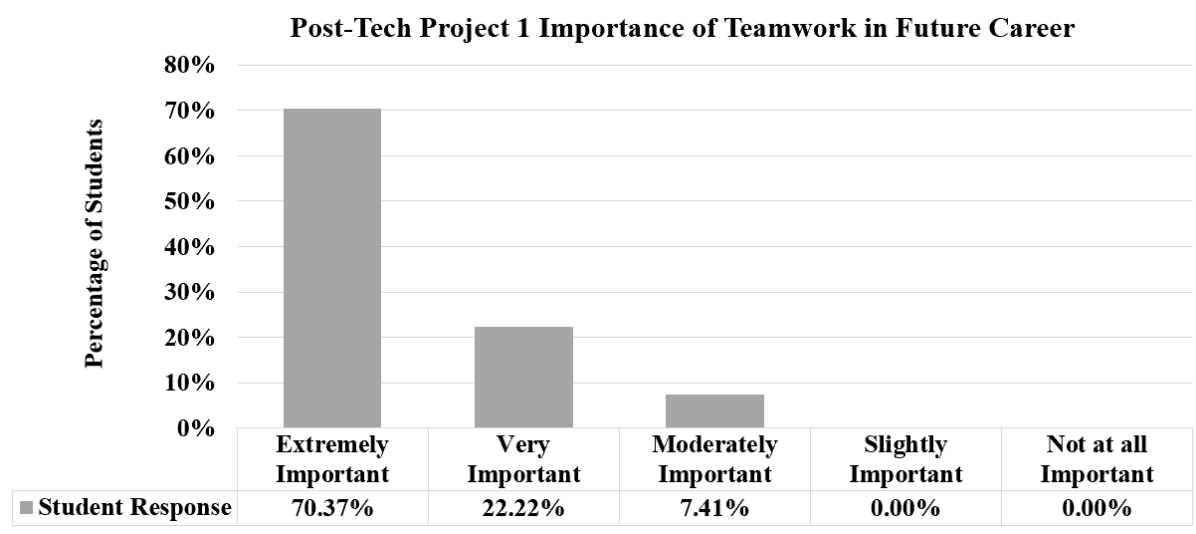

Fig. 6. Student Responses to Importance of Teamwork in Future Career

\subsection{Technical project 2 - Energy conversion}

The second technical project was centered around the concept of energy conversion. The goal of this technical project, from a student's perspective, was to design a system to convert heat to work and to provide a thermodynamic analysis of said system. The only heat source permitted for the project was a tea light candle. The task of the energy conversion machine was to raise a quarter. In order to maintain safety, groups were asked to submit a preliminary design for approval prior to the build or execution of the task. The final design was to be tested in class, a brief oral presentation prepared for describing the system, and the submission of a full written technical report analyzing the design and results

Students were asked a series of questions prior to the start of the project, as well as after completion of the project. The responses represent how the students evaluated themselves for their level of knowledge of energy conversion, their understanding of heat and work, and their comfort level in building an energy conversion machine. The students gauged their knowledge based on an eleven-point Likert scale, where a $(0)$ corresponds to a beginner's level of knowledge and (10) being an expert level of knowledge. Figure 7 depicts the results for the student's self-evaluation pertaining to their knowledge of energy conversion. Prior to the second technical project, $43.92 \%$ of students considered themselves to an understanding at a level of (7) or moderately high level. The completion of the technical project yielded that $58.09 \%$ of students, attained this elevated level of understanding, an increase of $14.17 \%$, due to the scaffolded learning environment produced within the course as indicated through student responses. 


\section{Pre-Tech Project 2 Level of Knowledge of Energy Conversion}

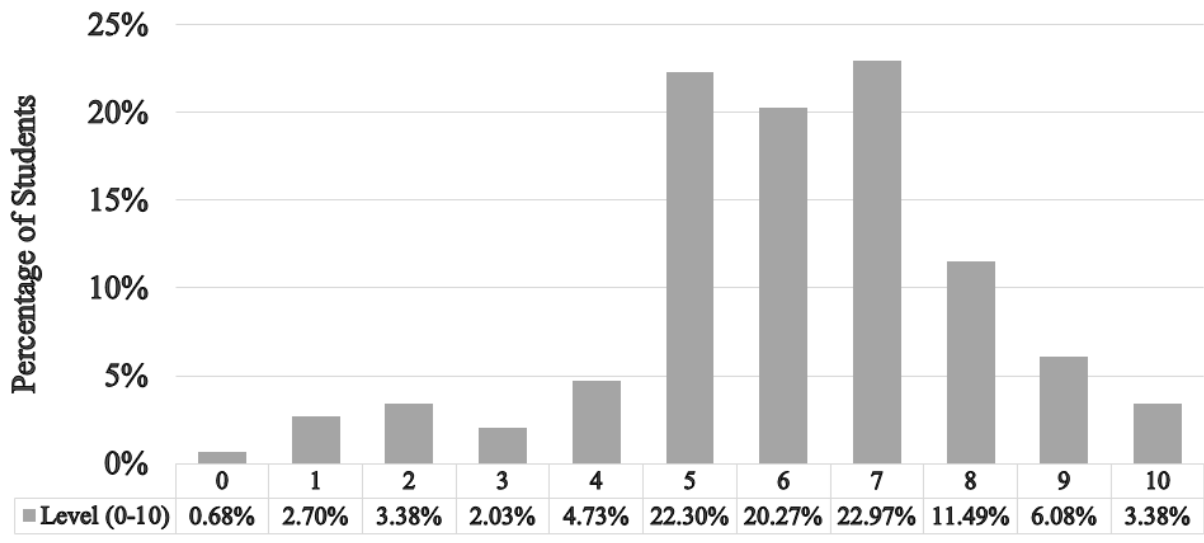

\section{Post-Tech Project 2 Level of Knowledge of Energy Conversion}

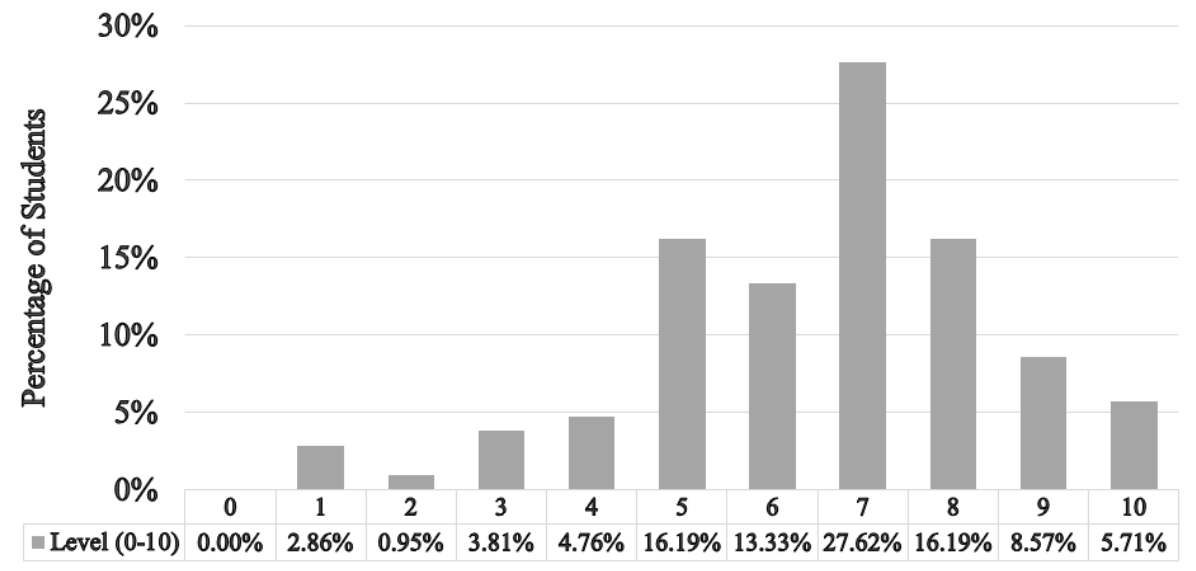

Fig. 7. Student Responses to Level of Knowledge of Energy Conversion

Students were also asked to record their comfort level in building an energy conversion machine. Figure 8 depicts the self-reported comfort level of the students during this challenge. The second technical project provided students with exposure to a progressive experiential learning model [32], where they were able to improve their competencies within the area of energy conversion. The more competent a student is within a specific area, the more comfortable they are in performing tasks within said area. In general, students within the technology discipline benefit from this type of learning model. The scale reported on the surveys is the same eleven-point Likert used previously and ranges from a student feeling no comfort at all, to an extremely high level of comfort. Prior to the technical project, $32.42 \%$ of students reported a comfort level of (7) or greater level of comfort. Whereas after the project, $51.93 \%$ of the students reported a moderately high comfort level of (7) or higher. Furthermore, the number of students who indicated a comfort level of (5) or less was decreased by $25.12 \%$ as a result of the technical project. The evaluation of students understanding within heat and 
work before and after the technical project produced similar improvements. Figure 9 depicts self-reported understanding level of heat and work pre and post technical project one the same eleven-point scale. As a result of the second technical project, a $10.07 \%$ increase in students reporting a comfort level of (7) or higher was found.

\section{Pre-Tech Project 2 Comfort Level in Building a Machine for} Energy Conversion

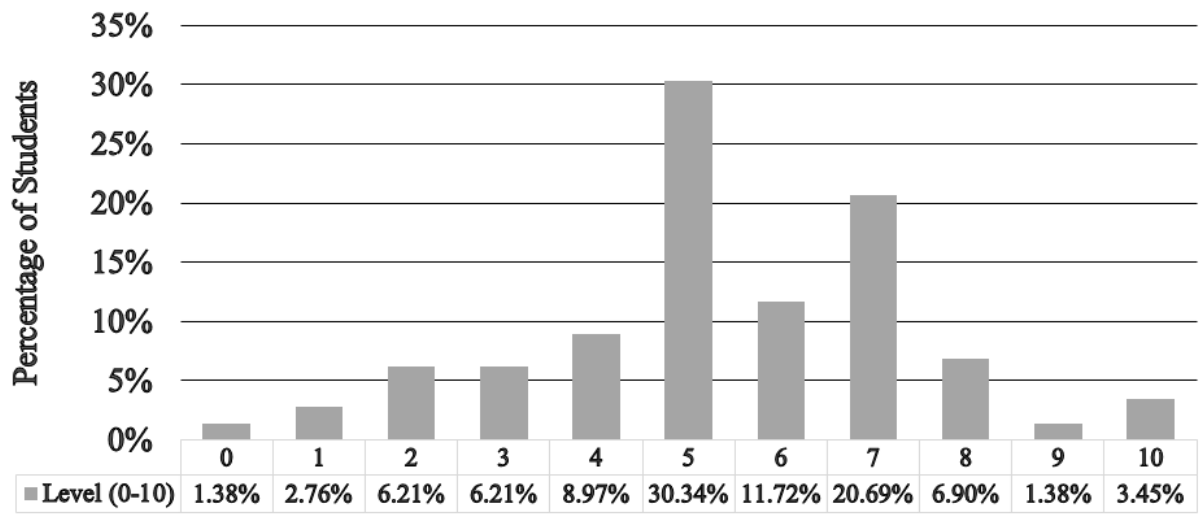

Post-Tech Project 2 Comfort Level in Building a Machine for Energy Conversion

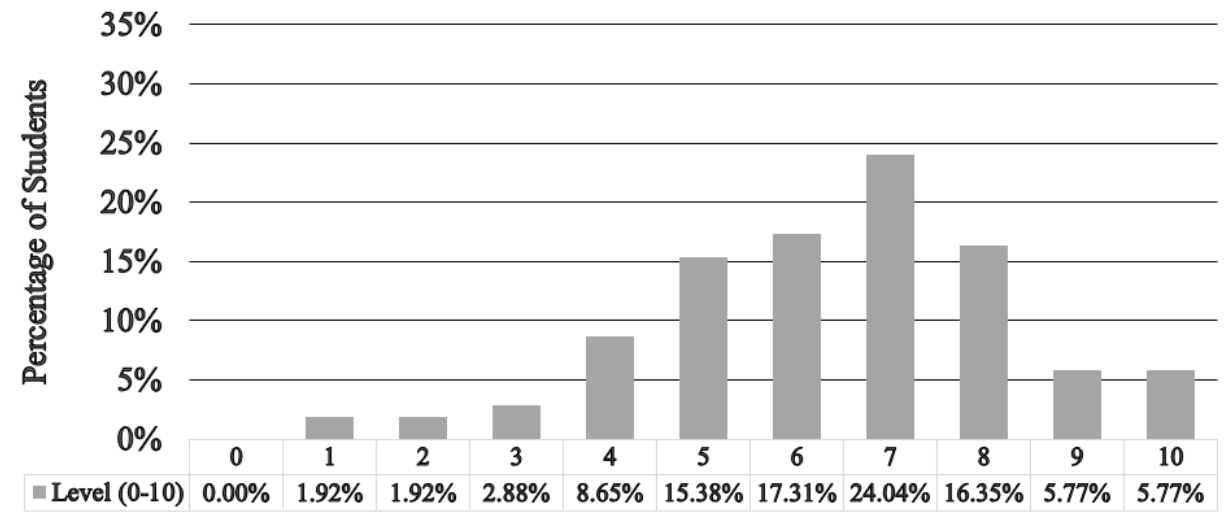

Fig. 8. Student Responses to Comfort Level in Building an Energy Conversion Machine 

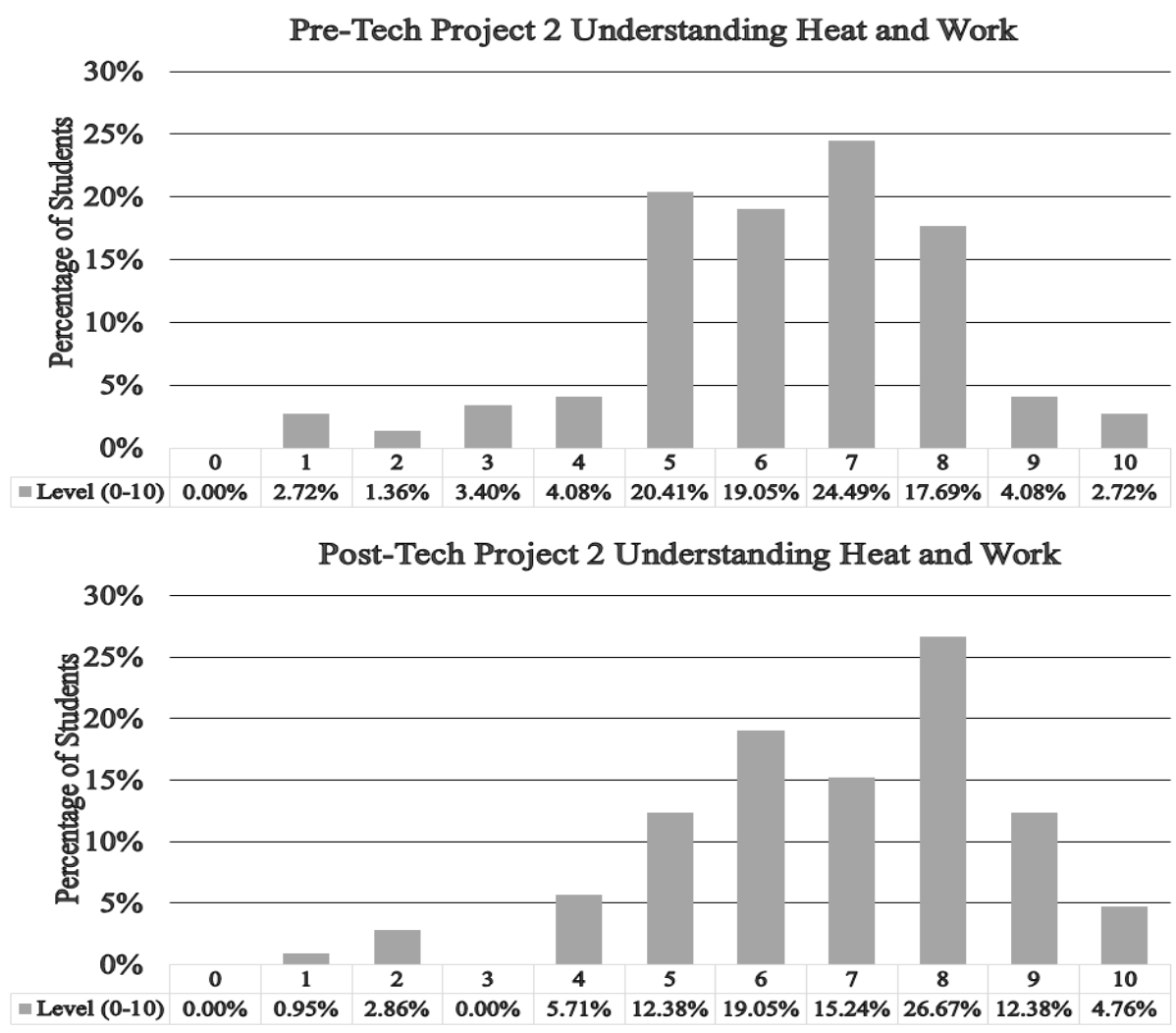

Fig. 9. Student Responses to Understanding of Heat and Work

Short answer responses indicated that many students were challenged by this course, but through incorporating technical projects, students felt they were able to fully grasp the course concepts. In referring to the Stirling engines and the further understanding of heat and work one student stated, "The exercise was interesting in that it provided hands on experience with it and allowed one to see "it happens in real time"". An additional aspect of the technical projects that the students found to help their problemsolving skills as well as with the progression of complex concepts through the cognitive process dimension was the freedom to apply the concepts being learned. "It was interesting to apply concepts we learned ourselves and not have to follow a set of instructions..." is how another student viewed the learning environment.

\subsection{Overall course surveys}

Quantitative metrics given within the end of the semester surveys assessed students' overall impression of the technical projects and how they impacted their perceived learning. During these projects' students noted that they learned "thermodynamics is everywhere". Some said that MET 32000 was "like that of the prerequisite course" while others said, "it was well taught, and they appreciated the real-world examples 
and content." Attempts for evaluating the transformation as a result of the class projects, students were asked how they would rate the level of class participation/interaction. The most common response was a level (7), a moderately high level of interaction as depicted in Figure 10. This level could be increased in the future through the addition of display cycle models, class problems, and demonstrations. However, for a lecture only course the interaction level was relatively high and was thus reflected by the student comments. $64.34 \%$ of students stated that the real-world example problems from the instructor and text enhanced their learning. Furthermore, 23.8\% stated that their learning may have been enhanced directly from these methods. The student responses reflect a widespread increase in learning, expressed by the students, as a result of applied learning.

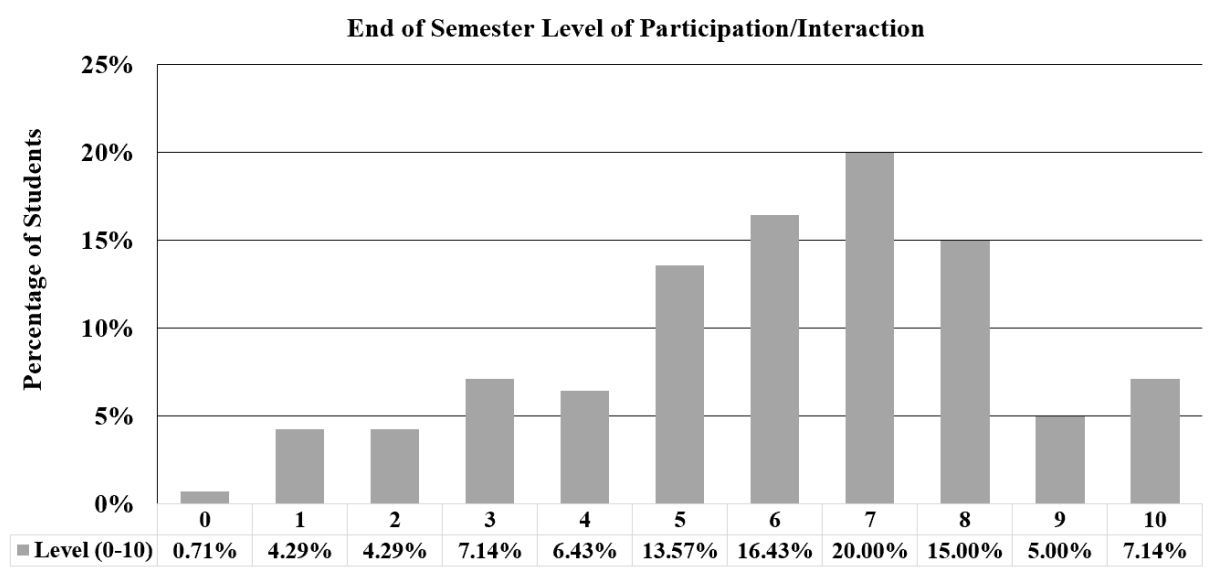

Fig. 10. Student Assessment of Interaction

Students were also asked if the use of real-world examples enhanced their learning. Consistently, students felt that using the technical projects to present the very theoretical thermodynamic concepts in real-world applications did enhanced their learning. The self-reported enhanced learning responses shown in Figure 11 were further supported through the student's qualitative responses, where students highlighted that the technical projects helped them begin to see all the ways in which thermodynamics impacts their everyday life. Students explained the impact the technical projects have on their outlook of thermodynamics and the learning environment used to do so as:

"I can't motivate myself to learn something if I can't apply it in my mind. The realworld problems help me apply it internally"

"I was able to make a connection with what I was learning because I could see where it was going with the information. I was able to maintain interest in problems because they weren't just words and numbers on paper, they were situations in the real world" 


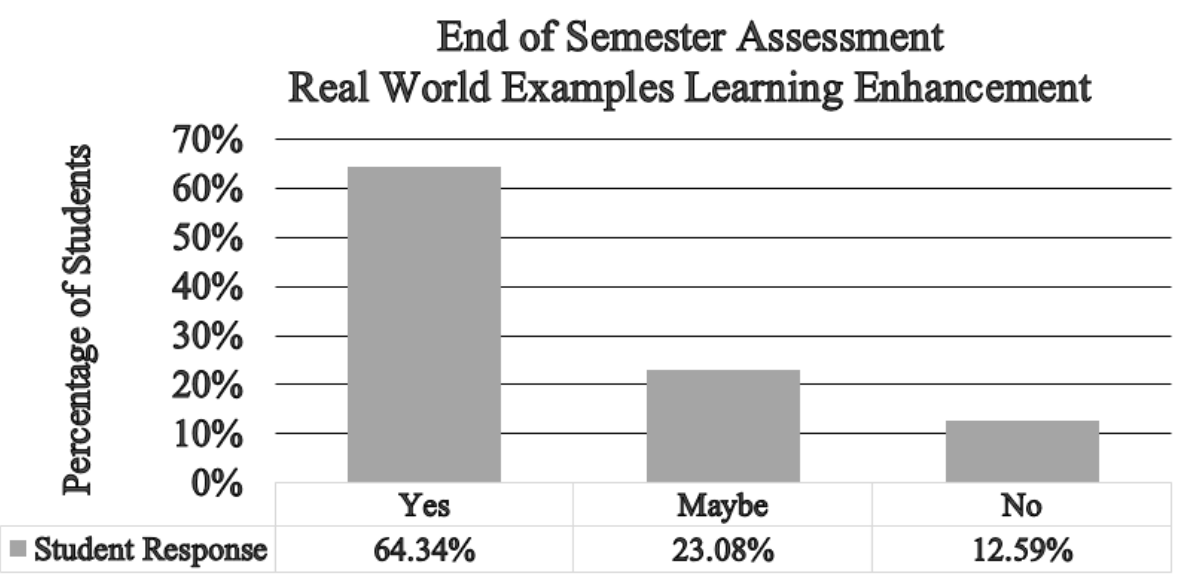

Fig. 11. Student Assessment on Real-world Examples

Students felt that working on the technical projects as a team improved the overall takeaways of the two projects. Within teams, there is always dissatisfaction and disappointment when not all members participate. Therefore, per design, the structure of the technical projects promoted contributions from all colleagues. While the lack of participation can still occur, many students felt the projects brought all the members together. Student indications showed that teaming produced diverse ideas and skill sets to accomplish the challenges. The students also reported on the practicality of team-based learning during their time within the engineering technology program, stating that "Working in a team is something every student going into an engineering field should be prepared for, and this project only further strengthened that view".

\section{Discussion and conclusions}

To further our understanding of the student population, an assessment of the student provided information was completed producing the following results per Maynard et al., [3]:

- Students within this population range in age from 17 to 30 years old and contained no outliers.

- Slightly over $90 \%$ of all students identified as male.

- All students involved within the study are majoring in mechanical engineering technology and taking courses required within its curriculum.

- Most of the students in the class reported to be between their fifth and seventh semesters of the program.

Overall, the provided feedback showed that students understanding of renewable energy and heat and work conversions increased as a result of technical projects, lectures, and the Renewable Energy Certificate. The projects, as implemented, allow the instruc- 
tors to add an experiential learning component to the course, which has previously indicated to promote greater problem-solving skills among students [23]. The changes to the in-classroom environment allowed for students to more firmly grasp and learn how to apply the theoretical concepts seen within thermodynamics, concepts that are often thought to be the most difficult subjects to conceptually be understood [4]. The energy certificate program helped to promote a greater sense of intrinsic motivation, where students could collectively work through the theoretical complexities seen within thermodynamics. Like previously stated, students many times get stuck when it comes to complex problem solving within thermodynamics as the topics are very theoretical [5]. As a result of the transformation, students felt the technical projects, enhanced lectures, and certificate program were a way to more fully understand and not misinterpret these complex topics. The use of teaming within the technical projects allowed for students to actively communicate with one another to better solidify the content being applied in ways that may be more comprehensible to them as compared to similar feedback from an instructor [34]. Based off the responses gathered, there are still areas where improvements can be made to help increase the mean understanding level of students across the board.

Overall, the survey responses show that students felt their learning environment was enhanced as a result of applying thermodynamic concepts being taught through realworld hands-on examples. Future work will not only look to support these findings but will help researchers confirm the results and ensure they are not heavily influenced by biases, given the ways in which the quantitative and qualitative data was captured. There are many areas where biases may be present within research projects such as this. Student surveys are often time susceptible to encountering non-response biases as the surveys cannot be forced.

To answer the first research question, do project-based experiences influence the learning of engineering technology students in thermodynamics, the data revealed that students felt as if the projects did influence learning. The quantitative data supported that the project-based learning model used within the course increased the perceived learning of students. In addition, the qualitative responses indicated the same finding. Following are responses from two students on the use of technical projects to influence the learning of thermodynamic concepts.

"I enjoy the use of the technical projects in the class because it allows for teamwork and real-world application. I tend to grasp that better than normal bookwork"

"It helped you visualize what you are actually learning"

This therefore indicates the answer to the first research question, that the technical projects do influence the learning of engineering technology students. Technical projects allowed for the course material to be more effectively conveyed to the students based on their style of learning. Moreover, the hands-on pedagogical approach used in the projects, improved the student's motivation and attention within the class [35].

The answer to the second research question, do real-world, experimental projects improve engineering technology students understanding of thermodynamic concepts, is answered as well. Students do find that they have a greater understanding of the complex thermodynamics concepts when being taught through real-world applications as they can actualize the concepts, thus providing them with a pragmatic understanding 
[36]. Students expressed this improved understanding using real-world projects explaining:

"It helped me be able to relate the topics to something I was familiar with"

"It helped provide examples of how the project was supposed to work and helped one come up with a variety of different ideas to test out"

"Making sure theoretical points are explained in real world applications helps people understand much better than just a theoretical explanation"

The real-world examples improved understanding by allowing students to meet course objectives along a continuum from simple to complex and concrete to abstract [22]. This progression through experiential learning encourages students to become more competent within the area of thermodynamics [32]. Student competency betters as they remember the concepts being taught in class, and through the technical projects, applying them to create physical representations of the theoretical concepts being learned. Working on real-world examples allowed for students to not only grow in terms of their specific knowledge but provided growth opportunities as engineers by working through these complex problems that have multiple different pathways to success [10].

\subsection{Future work}

The results of this research including implementation of renewable energy topics, technical projects, certifications, and baseline energy knowledge are being used as a steppingstone for future works. One such future work is the inclusion of a common energy theme throughout the Mechanical Engineering Technology curriculum which will allow for production of a scaffolded learning environment for the students in more than the two classes in focus, thus allowing the courses to become vertically and horizontally integrated around the centralized theme of energy. Furthermore, students may feel strongly one way or another about the course, the projects or even the instructors, all of which are potential biases due to surveys being voluntary response. An area being looked at currently through this work and future work in this area are straight response biases. As Likert based surveys measure a student's response on a pre-defined scale, any time values of only one type are recorded and could be potential for this type of bias. This type of bias is difficult to validate as a student's perception is their own. A potential method of mitigation is to have questions that do not address the student's perception but rather ask them to indicate a specific response as proof of reading the question.

It should also be indicated, based on the promising results presented, that a future component of this research effort will be to collect follow-up data from ensuing courses where these changes have been made and to assess the effects of team behavior on perceived learning. A follow-up study with identical course alterations will aid in validating and further understanding the results presented. This article focused on student's perception of the learning environment which was collected through surveys. Beyond the scope of this article, which was centered around the self-reported perception, students were quantitatively assessed based on their displayed understanding of thermodynamic concepts as indicated within the outline of the two technical projects. The use 
and analysis of these real-world indicators of the learned concepts could further aid in confirming the positive impacts the course modifications made. Such findings should be presented within future publications.

\section{$7 \quad$ References}

[1] Shehadi, Maher, and Anne Lucietto. "Engineering technology students' response to handson fluid power exercises." International Journal of Engineering and Advanced Technology 7 , no. 5 (2018).

[2] Anne M. Lucietto, Jennifer Drapinski Moss, and Mark French. "Examining Engineering Technology Students: How They Perceive and Order Their Thoughts." Association for Engineering Education - Engineering Library Division Papers, 2017, Association for Engineering Education - Engineering Library Division Papers, 2017-06-24. https://doi.org/10.18260/ $1-2--27418$

[3] Moran, M. J., \& Tsatsaronis, G. (2017). “Engineering thermodynamics.” In CRC Hand-book of Thermal Engineering, pp. 1-112. 2017.

[4] Saricayir, Hakan, Ay, Selahattin, Comek, Arif, Cansiz, Gokhan, and Uce, Musa. "De-termining Students' Conceptual Understanding Level of Thermodynamics." Journal of Education and Training Studies 4, no. 6 (2016): Journal of Education and Training Studies, 201603-22, Vol.4 (6). https://doi.org/10.11114/jets.v4i6.1421

[5] Lawanto, Oenardi, Minichiello, Angela, Uziak, Jacek, and Febrian, Andreas. "Students' Task Understanding during Engineering Problem Solving in an Introductory Thermodynamics Course." International Education Studies 11, no. 7 (2018): 43. https://doi.org/ $\underline{10.5539 / \text { ies.v } 11 \mathrm{n} 7 \mathrm{p} 43}$

[6] Lawlor, John, Marshall, Kevin, and Tangney, Brendan. "Bridge21 - Exploring the Po-tential to Foster Intrinsic Student Motivation through a Team-based, Technology-mediated Learning Model." Technology, Pedagogy and Education 25, no. 2 (2016): 187-206. https://doi.org /10.1080/1475939x.2015.1023828

[7] Alvarez-Bell, Rosa, Wirtz, Derrick, and Bian, Hui. "Identifying Keys to Success in In-novative Teaching: Student Engagement and Instructional Practices as Predictors of Student Learning in a Course Using a Team-Based Learning Approach." Teaching and Learning Inquiry 5, no. 2 (2017): 128-46. https://doi.org/10.20343/teachlearningqu.5.2.10

[8] Sumtsova, Olga V, Aikina, Tatiana Yu, Bolsunovskaya, Liudmila M, Phillips, Chris, Zubkova, Olga M, and Mitchell, Peter J. "Collaborative Learning at Engineering Universities: Benefits and Challenges." International Journal of Emerging Technologies in Learning 13, no. 1 (2018): 160-77. https://doi.org/10.3991/ijet.v13i01.7811

[9] Flowers, Nancy, Mertens, Steven B, and Mulhall, Peter F. "The Impact of Teaming: Five Research-Based Outcomes." Middle School Journal 31, no. 2 (1999): 57-60. https://doi.org/ $\underline{10.1080 / 00940771.1999 .11494619}$

[10] Jesper, Larsen Abilgaard, Nielsen, Jens Frederik Dalsgaard, and Zhou, Chunfang. "Motivating Students to Develop Satellites in Problem and Project-Based Learning (PBL) Environment." International Journal of Engineering Pedagogy 3, no. 3 (2013): 11-17. https://doi. org/10.3991/ijep.v3i3.2529

[11] Morrison, J. "Attributes of STEM education: The student, the school, the classroom." TIES (Teaching Institute for Excellence in STEM) 20 (2006): 2-7. 
[12] Jackson, Shari L., Joseph Krajcik, and Elliot Soloway. "The design of guided learner-adaptable scaffolding in interactive learning environments." In Proceedings of the SIGCHI conference on Human factors in computing systems, pp. 187-194. 1998. https://doi.org/10.1145/ 274644.274672

[13] Trif, Letitiţia. "Training Models of Social Constructivism. Teaching Based on Develop-ing A Scaffold." Procedia, Social and Behavioral Sciences 180 (2015): 978-83. https://doi.org/ 10.1016/i.sbspro.2015.02.184

[14] Vygotsky, L. S, Cole, Michael, John-Steiner, Vera, Scribner, Sylvia, and Souberman, Ellen. Mind in Society. Cumberland: Harvard University Press, 1978.

[15] Hart Research Associates, "Falling Short? College Learning and Career Success," in "Selected Findings from Online Surveys of Employers and College Students Conducted on Behalf of the Association of American Colleges \& Universities," 2015.

[16] Salas, Eduardo, Burke, C. Shawn, and Cannon-Bowers, Janis A. "Teamwork: Emerging Principles." International Journal of Management Reviews: IJMR 2, no. 4 (2000): 339-56.

[17] Bell, Philip, Bruce Lewenstein, Andrew W. Shouse, and Michael A. Feder. Learning science in informal environments: People, places, and pursuits. Vol. 140. Washington, DC: National Academies Press, 2009. https://doi.org/10.1177/0963662510361428

[18] Aleryani, Arwa Y, and AlMunifi, Abdullatif A. "A Roadmap to the Development of Key Competencies of Engineering and Technology Graduates." International Journal of Engineering Pedagogy 9, no. 5 (2019): 75-88. https://doi.org/10.3991/ijep.v9i5.11094

[19] Ellis, Aleksander P. J, Hollenbeck, John R, Ilgen, Daniel R, Porter, Christopher O. L. H, West, Bradley J, and Moon, Henry. "Team Learning." Journal of Applied Psychology 88, no. 5 (2003): 821-35.

[20] Zafft, Carmen R, Adams, Stephanie G, and Matkin, Gina S. "Measuring Leadership in Selfmanaged Teams Using the Competing Values Framework." IEEE Engineering Management Review 39, no. 1 (2011): 46-58. https://doi.org/10.1109/emr.2011.5729973

[21] Ford, Kate. "Competency-based education: History, opportunities, and challenges." UMUC Center for Innovation in Learning and Student Success 10 (2014): 24.

[22] Anderson, L. W., Krathwol, D., Airisian, P., Cruikshank, K., Meyer, R., Printrich, P. et al. "A Taxonomy for Learning, Taeching, and Assesing." ed: New York: Longman, 2001.

[23] J. Durkin, Robert, and Verma, Aakash. "Experiential Learning in Engineering Technol-ogy: A Case Study on Problem Solving in Project-Based Learning at the Undergraduate Level." Journal of Engineering Technology 6, no. 1 (2016): 1-5. https://doi.org/10.21859/jet-06018

[24] Krathwohl, David R. "A Revision of Bloom's Taxonomy: An Overview." Theory into Practice 41, no. 4 (2002): 212-18.

[25] Pinho-Lopes, Margarida, and Macedo, Joaquim. "Project-Based Learning to Promote High Order Thinking and Problem Solving Skills in Geotechnical Courses." Internation-al Journal of Engineering Pedagogy 4, no. 5 (2014): 20. https://doi.org/10.3991/ijep.v4i5.3535

[26] Scott Freeman, Sarah L. Eddy, Miles McDonough, Michelle K. Smith, Nnadozie Okoroafor, Hannah Jordt, and Mary Pat Wenderoth. "Active Learning Increases Student Performance in Science, Engineering, and Mathematics." Proceedings of the National Academy of Sciences - PNAS 111, no. 23 (2014): 8410-415. https://doi.org/10.1073/pnas.1319030111

[27] Maynard, Cole, Brittany Newell, Anne Lucietto, William Hutzel, and Jose Garcia-Bravo. "Applied Learning within Thermodynamics: A Perspective on Energy Con-cepts." In 2018 IEEE Frontiers in Education Conference (FIE), pp. 1-8. IEEE, 2018. https://doi.org/10.1109/ fie.2018.8658922

[28] NREL. (n.d.) PVWatts Calculator. Retrieved 2018-4-8, from https://pvwatts.nrel.gov/.

[29] Krippendorff, Klaus. Content Analysis: An Introduction to Its Methodology. 3rd ed. Los Angeles; London: SAGE, 2013. 
[30] Norman, Geoff. "Likert Scales, Levels of Measurement and the "laws" of Statistics." Advances in Health Sciences Education: Theory and Practice 15, no. 5 (2010): 625-32.

[31] Taheri, Pooya. "Project-Based Approach in a First-Year Engineering Course to Promote Project Management and Sustainability." International Journal of Engineering Pedagogy 8, no. 3 (2018): 104-19. https://doi.org/10.3991/ijep.v8i3.8573

[32] K. G. Frase, R. M. Latanision, and G. Pearson, "Engineering Technology Education in the United States," National Academies Press, Washington, D.C.2016, Available: http://www. nap.edu/23402

[33] Neuendorf, Kimberly A. The Content Analysis Guidebook. 2nd ed. 2017.

[34] Kandakatla, Rohit, Berger, Edward J, Rhoads, Jeffrey F, and DeBoer, Jennifer. "Stu-dent Perspectives on the Learning Resources in an Active, Blended, and Collaborative (ABC) Pedagogical Environment." International Journal of Engineering Pedagogy 10, no. 2 (2020): 7-31. https://doi.org/10.3991/ijep.v10i2.11606

[35] Reeve, Johnmarshall, and Lee, Woogul. "Students' Classroom Engagement Produces Longitudinal Changes in Classroom Motivation." Journal of Educational Psychology 106, no. 2 (2014): 527-40. https://doi.org/10.1037/a0034934

[36] Membrillo-Hernández, Jorge, Ramírez-Cadena, Miguel De Jesús, Caballero-Valdés, Carlos, Ganem-Corvera, Ricardo, Bustamante-Bello, Rogelio, Benjamín-Ordoñez, José Antonio, and Elizalde-Siller, Hugo. "Challenge-based Learning: The Case of Sustaina-ble Development Engineering at the Tecnologico De Monterrey, Mexico City Campus." International Journal of Engineering Pedagogy 8, no. 3 (2018): 137-44. https://doi.org/10.3991/ijep $\underline{. \mathrm{v} 8 \mathrm{i} 3.8007}$

\section{Authors}

Cole Maynard is a 1st year doctoral student in the School of Engineering Technology at Purdue University. Cole is an Indiana native, who was born and raised in Marion IN. He received his Bachelors of Science degree in Electrical Engineering Technology from Purdue University in May of 2017 and MS in 2019. Cole is currently working on a sponsored research project in development of new materials for 3D printed sensors.

Jose Garcia received a B.S. in Mechanical Engineering from Universidad de Los Andes in 2002Bogota, Colombia, and M.Sc. in Engineering and Ph.D. degrees from Purdue University West Lafayette, IN, USA. in 2006 and 2011 respectively. From 2011 to 2012, he was a Research Assistant Professor at the Illinois Institute of Technology. Since 2015, he has been an Assistant Professor with the School of Engineering Technology at Purdue University, West Lafayette. His research interests include electric and hydraulic hybrid drive trains, Additive manufacturing of hydraulic and pneumatic components and energy efficiency and duty cycles of hydraulic systems.

Anne Lucietto received a B.S. in Mechanical Engineering from Marquette University, an MBA in Finance from Lewis University, and a Ph.D. in Engineering Education with a technical concentration in Materials Engineering from Purdue University, West Lafayette, IN. She held progressively responsible positions in industry focusing on maintenance, construction, and facility engineering in nuclear power, federal research laboratory, and a variety of large manufacturing/process corporations of varying sizes. During this time, she was a part time adjunct instructor in engineering and mathematics 
moving into a full-time position at Purdue University (School of Engineering Technology) in 2014. She conducts research on the student population and works on projects in technical curriculum development, materials, and renewable energy.

William Hutzel received a B.S. and M.S. degree from The Pennsylvania State University in 1986 and 1989 respectively. He is a Professional Engineer and Professor of Mechanical Engineering Technology at Purdue University, West Lafayette, IN where he teaches thermodynamics and conducts research into building automation, indoor air quality, and solar energy for achieving net zero energy buildings.

Brittany Newell received a B.S. degree in Biomedical Engineering, a M.Sc. and Ph.D. in Agricultural and Biological Engineering from Purdue University West Lafayette, IN, in 2009, 2010, and 2012 respectively. From 2013 to 2015, she worked for a contract manufacturing company in quality and regulatory engineering and as a Quality Manager. In 2015, she returned to Purdue as an Assistant Professor with the school of Engineering Technology. Her research interests are intelligent sensors and actuators, adaptive structures, additive manufacturing, and energy efficiency. Dr. Newell is interested in implementation of these technologies into industrial applications.

Article submitted 2020-06-24. Resubmitted 2021-03-02. Final acceptance 2021-09-10. Final version published as submitted by the authors. 